\title{
Simulation of single-phase shunt active power filter with fuzzy logic controller for power quality improvement
}

\begin{abstract}
With the proliferation of power electronics devices used for industrial, commercial and residential purposes have led to the deterioration of supply current and voltage wave forms, and this caused power quality problems within the supply system. Traditional passive filter was the earliest solution for mitigating harmonics produced by non-linear loads, but passive filter have the disadvantages of series and parallel resonances with the supply source impedance and it's heavy in size. Due to these problems in passive filter, it applications becomes very limited. With the introduction of shunt active power filter, harmonics mitigations of the current and voltage distortion wave forms can therefore be suppressed. In this paper, the modeling and simulation of single-phase shunt active power filter controlled with fuzzy logic controller using MATLAB SIMULINK fuzzy inference system (FIS), as against many literatures that used MATLAB fuzzy tool box environment is proposed. A modified three-phase to one-phase synchronous reference frame for the extraction of the harmonics was introduced in this paper. The control algorithm for the proposed shunt active power filter has shown its feasibility in suppressing harmonics produced by non-linear loads. Results of the total harmonic distortion (THD \%) for the simulations found to be within the recommended imposed IEEE 519-1992 harmonic standard.
\end{abstract}

Keyword: Shunt active power filter; Harmonics; Power quality; THD; Fuzzy logic controller 